\title{
Comparative electrophysiological responses in anisometropic and strabismic amblyopic children
}

This article was published in the following Dove Press journal:

Clinical Ophthalmology

30 June 2017

Number of times this article has been viewed

\author{
Luiz Cláudio Santos de \\ Souza Lima' \\ Adalmir Morterá Dantas ${ }^{2}$ \\ Guilherme Herzog Neto' \\ Eduardo França \\ Damasceno' \\ Helena Parente Solari' \\ Marcelo Palis Ventura' \\ 'Department of General Surgery, \\ Federal Fluminense University, \\ Niteroi, ${ }^{2}$ Department of \\ Ophthalmology, Federal University of \\ Rio de Janeiro, Rio de Janeiro, Brazil
}

Correspondence: Luiz Cláudio Santos de Souza Lima

Federal Fluminense University, Rua

Conde de Bonfim 193, I201 Tijuca,

Rio de Janeiro 20520-050, RJ, Brazil

$\mathrm{Tel}+5521988196643$

Email comitante@gmail.com
Purpose: To compare anisometropic hypermetropic amblyopic and strabismic amblyopic responses to pattern electroretinogram (PERG) and pattern visual evocated potential (PVEP).

Materials and methods: Fifty-six patients - 18 hypermetropic anisometropic amblyopic

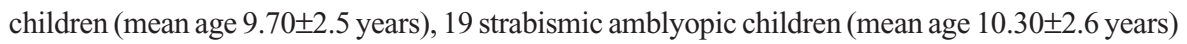

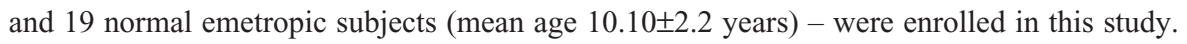
After routine ophthalmic examination, PERG and PVEP were recorded in response to checks reversed at the rate of two reversals/second stimulating macular area.

Results: The difference between hypermetropic anisometropic amblyopia and strabismus amblyopia with respect to $\mathrm{P} 100 / \mathrm{P} 50 / \mathrm{N} 95$ wave latencies $(P=0.055 / 0.855 / 0.132)$ and $\mathrm{P} 100 / \mathrm{P} 50 /$ N95 amplitudes $(P=0.980 / 0.095 / 0.045)$ was not statistically significant. However, there was a significant statistical difference between strabismic amblyopia group and controls for P100/ P50/N95 latencies $(P=0.000 / 0.006 / 0.004)$.

Conclusion: Our findings indicated that despite clinical differences between anisometropic amblyopic and strabismic amblyopic patients, no differences were found in the responses of PVEP and PERG. The abnormal components of the PVEP and PERG in amblyopic subjects could reflect a retinal dysfunction in the visual pathway.

Keywords: amblyopia, strabismus, pattern electroretinogram, pattern visual evocated potential, anisometropia

\section{Introduction}

Amblyopia is a visual disorder defined as a decrease in visual acuity of one or both eyes that results from abnormal binocular interaction or pattern visual deprivation that occurs in the immature visual system of early childhood in eyes that appear typically normal. ${ }^{1,2}$ Amblyopia has a significant effect on psychosocial behavior, and therefore, early (before 4 years of age) visual testing is highly recommended for all children., Early strabismus and refractive errors are risk factors for unilateral amblyopia, whereas bilateral astigmatism and hyperopia are risk factors for bilateral amblyopia. ${ }^{5}$ Less common causes of visual deprivation such as eyelid ptosis and congenital cataracts may also result in amblyopia. ${ }^{6,7}$ Strabismus and anisometropia have different mechanisms of inducing amblyopia. ${ }^{8}$ Abnormal binocular interaction in strabismus generates suppression and amblyopia of the second diplopic image. ${ }^{9}$ On the other hand, unequal visual inputs that occur in anisometropia result in progressive suppression of the unfocused image of the ametropic eye that cannot harmonize with the image from the fellow eye. ${ }^{10}$ These two mechanisms may correspond to different anatomic locations for anisometropic and strabismus amblyopia. Although the anatomic basis of amblyopia seems to be located in the primary and secondary visual cortex, ${ }^{11}$ lateral geniculate nucleus dysfunction has been documented and retinal involvement may 
also be implicated. Abnormal macular structural images have been found using optical coherence tomography (OCT) in the amblyopic eye. ${ }^{12-16}$ These reports suggest that it is important to consider the relationship between possible structural anomalies and electrophysiological responses. ${ }^{17,18}$ Preganglionic-level retinal dysfunction may occur as suggested by reduction in the abnormal pattern electroretinogram (PERG) amplitude in the amblyopic eye. ${ }^{19}$ In this study, we propose to compare hypermetropic anisometropic amblyopic and strabismic amblyopic responses to PERG and pattern visual evocated potential (PVEP).

\section{Materials and methods Study design}

This is a cross-sectional study of 56 children. It followed the principles of Declaration of Helsinki for experimentation in humans and was approved by the Internal Ethical Committee Review Board of Antonio Pedro University Hospital of the Federal Fluminense University. Written informed consent was obtained from parents or guardians of all the volunteers. A complete comprehensive ocular examination including evaluation of best-corrected visual acuity, ocular motility and pupillary reflexes, slit lamp biomicroscopy, fundus examination and evaluation of cycloplegic refraction was conducted. Patients in the strabismic amblyopia group were esotropic and were treated for amblyopia before and after having undergone strabismic surgery by the same surgeon (LCSSL) and in the same hospital. Some minimal degree of misalignment and amblyopia persisted until the time of the study. Anisometropic patients were previously treated with corrective spectacles and occlusion. All subjects were assigned to one of the following three groups: 1) hypermetropic anisometropic amblyopic group $(n=18), 2)$ strabismusrelated amblyopic group $(n=19)$ and 3$)$ normal emetropic controls $(n=19)$. Amblyopia was defined as a loss of the best-corrected visual acuity of greater than or equal to two lines on the visual acuity chart. Anisometropic amblyopia was defined as a refractive difference of $(+) 1.5$ diopters with a spherical equivalent correction. Visuscopy was performed to determine the quality of fixation and exclude eccentric foveal fixation. Table 1 shows the group demographic and clinical data. Patients who had a history of intraocular surgery, neurological disease, retinal disease, glaucoma and nystagmus were excluded from the study.

\section{Electrophysiological exams}

To minimize diurnal variations, testing was conducted between 13:00 and 15:00 hours. Electrophysiologic tests were registered when the child was considered to be alert and cooperative. Pupil-modifying drugs and eye drops were not used before or during the examinations. PVEP and PERG were recorded at the Electrophysiological Laboratory of the Niterói Eye Hospital with a Nihon Kohden (Meb-7102K Neuropack 2) electrophysiological apparatus in accordance with the PERG and PVEP International Society for Clinical Electrophysiology of Vision standards. ${ }^{20-22}$ The checkboard pattern stimulus was black and white with a check size of $16^{\prime}$ arc for a distance of $1 \mathrm{~m}$. Monocular stimulation was performed after a 10-minute adaptation period in a semi-dark and acoustically isolated environment. Reverse checkerboard patterns $(80 \%$ contrast and $110 \mathrm{~cd} / \mathrm{m}^{2}$ mean luminance) were generated by a Cathodic Ray Tube (CRT) with a 75-Hz frame rate and two reversals per second. The standard PERG transient response was recorded using loop electrodes hooked to the eyelid into the lower fornix and in contact with the bulbar conjunctiva $5 \mathrm{~mm}$ below the corneal limbus. The electrodes were sterilized before and after each test.

Data were evaluated with Kruskal-Wallis and MannWhitney test for group analyses with SPSS 20. Bonferroni correction was applied to minimize multiple-comparison test interference. The correlation between visual acuity and PVEP P100 latency was determined using Pearson's correlation coefficient. A $P$-value of $<0.017$ was considered statistically significant.

\section{Results}

A low positive correlation was found between visual acuity and PVEP P100 latency determined by Pearson's correlation coefficient $(r=0.45, P=0.001)$.

Table I Demographics and clinical data

\begin{tabular}{|c|c|c|c|c|c|}
\hline & \multirow[t]{2}{*}{ Control } & \multicolumn{2}{|l|}{ Strabismic } & \multicolumn{2}{|l|}{ Anisometropic } \\
\hline & & Amblyopic eye & Fellow eye & Amblyopic eye & Fellow eye \\
\hline Visual acuity (logMAR) & 0.0 & $0.44 \pm 0.3$ & $0.01 \pm 0.0$ & $0.48 \pm 0.2$ & $0.02 \pm 0.0$ \\
\hline Refractive error ${ }^{\mathrm{a}}(\mathrm{SE})$ & $0.25 \pm 0.3$ & $0.82 \pm 0.6$ & $0.66 \pm 0.6$ & $4.46 \pm 2.3$ & $3.04 \pm 2.3$ \\
\hline Age (years) & $10.10 \pm 2.2$ & $10.30 \pm 2.6$ & & $9.70 \pm 2.5$ & \\
\hline Sex (male/female) & $15 / 4$ & $10 / 9$ & & $10 / 8$ & \\
\hline
\end{tabular}

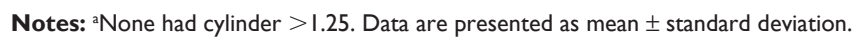

Abbreviation: SE, spherical equivalent. 
Table 2 Electrophysiological differences between controls, amblyopic eye and fellow eye

\section{Groups, $\mathbf{N}=56$}

\begin{tabular}{|c|c|c|c|c|c|}
\hline & \multirow[t]{2}{*}{ Control, $\mathbf{N}=19$} & \multicolumn{2}{|c|}{ Strabismic, $N=19$} & \multicolumn{2}{|c|}{ Anisometropic, $\mathbf{N}=18$} \\
\hline & & Amblyopic eye & Fellow eye & Amblyopic eye & Fellow eye \\
\hline PI00-PVEP latency (ms) & $105.28 \pm 14.9$ & $130.68 \pm 21.9$ & $110.37 \pm 14.8$ & $118.0 \pm 18.2$ & $104.7 \pm 8.3$ \\
\hline PI00-PVEP amplitude $(\mu \mathrm{V})$ & $12.81 \pm 7.3$ & $8.96 \pm 6.2$ & $11.88 \pm 7.9$ & $12.22 \pm 6.8$ & $13.88 \pm 4.2$ \\
\hline P50-PERG latency (ms) & $49.40 \pm 7.0$ & $59.12 \pm 15$ & $45.88 \pm 5.0$ & $57.26 \pm 12.7$ & $47.8 \pm 7.4$ \\
\hline P50-PERG amplitude (ms) & $2.28 \pm 1.4$ & $2.09 \pm 1.6$ & $3.1 I \pm 1.8$ & $2.64 \pm 1.2$ & $2.34 \pm 1.1$ \\
\hline N95-PERG latency (ms) & $92.61 \pm 15.6$ & $|24.8| \pm 39.4$ & $104.45 \pm 24.7$ & $104.8 \pm 1.7$ & $95.59 \pm 16.9$ \\
\hline N95-PERG amplitude $(\mu \mathrm{V})$ & $4.02 \pm 1.7$ & $3.94 \pm I .4$ & $5.14 \pm 1.9$ & $4.53 \pm 1.7$ & $5.16 \pm 1.8$ \\
\hline
\end{tabular}

Note: Data are presented as mean \pm standard deviation.

Abbreviations: PVEP, pattern visual evocated potential; PERG, pattern electroretinogram.

Table 2 depicts the PVEP and PERG wave amplitudes and latencies of anisometropic amblyopic eyes, strabismic amblyopic eyes and controls. The data in the table show that there was a significant difference in the $\mathrm{P} 100(P=0.000)$ and P50/N95 $(P=0.006 / 0.004)$ wave latencies between the strabismic amblyopic eye and controls. However, there was no significant difference in the P100/P50/N95 wave amplitudes $(P=0.060 / 0.564 / 0.856)$ between the strabismic amblyopic eyes and controls.

The comparison between both amblyopic group and controls was statistically significant for P100/P50/N95 latencies $(P=0.001 / 0.008 / 0.007)$, but not for P100/P50 amplitudes $(P=0.117 / 0.147 / 0.770)$. We found no significant difference between both anisometropic hypermetropic amblyopia and strabismus amblyopia with respect to P100/P50/N95 wave latencies $(P=0.055 / 0.855 / 0.132)$ and $\mathrm{P} 100 / \mathrm{P} 50$ amplitudes $(P=0.980 / 0.095 / 0.045)$. The comparison between the $\mathrm{P} 100 / \mathrm{P} 50 / \mathrm{N} 95$ wave amplitudes $(P=0.117 / 0.416 / 0.750)$ and latencies $(P=0.543 / 0.416 / 0.876)$ of the fellow normal eyes and controls was also statistically significant.

\section{Discussion}

Our results are in accordance with previous papers ${ }^{23,24}$ that show a difference between the PVEP and PERG wave latencies of amblyopic eyes and controls, as well as no statistical difference in the P100/P50 wave amplitudes of controls and amblyopic eyes. The comparison between the P100/ P50 wave amplitudes and latencies of the amblyopic fellow normal eyes and controls was also statistically significant notwithstanding a persistent treatment with topical atropine and full- or part-time occlusion. All patients included in our study were able to maintain fixation during examinations, as well as being collaborative despite their age, which is important for obtaining electrophysiological responses. ${ }^{21}$ We believe that clinical differences among the anisometropic hypermetropic amblyopic and strabismic amblyopic patients did not have an influence on the PVEP and PERG results.
The P50 and N95 components of the PERG may be affected in different diseases and could reflect a dysfunction of the retinal ganglion cell. ${ }^{25}$ The N95 wave component is more sensitive to stimulus contrast and special frequency, which are both more specific of ganglion cell function. On the other hand, the P50 wave component is poorly sensitive to stimulus contrast, but more sensitive to luminance, a more characteristic response of the overall internal retina. ${ }^{26}$ Therefore, PERG offers an assessment of the central retinal function and transcription of the retinal ganglion cell activity. Normal PERG wave amplitudes of amblyopic eyes and controls recorded in our sample may be a reflection of individually optimized alignment and stability. ${ }^{27,28}$ In our series, PVEP responses were obtained by high spatial frequencies (16-minute check) that specially stimulate the macular region. This region has a larger cortical representation, and abnormal PVEP responses represent the function of macular region in amblyopes. Small check (ie, 15-minute check) of probably active small axons prevalent in the parvocellular system and prolonged latencies of the PVEP could suggest deficiency in specific group of neurons. ${ }^{29}$

Although our findings showed a low positive correlation between visual acuity and PVEP P100 latency, this weak correlation could not influence the results because the visual acuity was similar in both amblyopic groups.

It is known that the age of onset of amblyopia may influence the results of electrophysiological tests,,$^{30-32}$ and it is also of our knowledge that the age of amblyopia onset in cases of strabismus is often earlier than in anisometropic cases. ${ }^{33}$ For these reasons, during the enrollment phase of the study, many patients were excluded. In order to constitute more homogeneous groups without significant differences in age and visual acuity, we included patients with similar date of onset of amblyopia. As, in our study, the date of onset of amblyopia was recorded while interviewing the parents, we should consider that this can lead to misinformation about the exact time of onset of amblyopia. 
Future studies of amblyopia and electrophysiological tests can be developed comparing other types of visual function exams, including spatial visual function with low contrast and contrast-sensitive function.

\section{Conclusion}

Our findings indicated that despite clinical differences between the anisometropic amblyopia and strabismic amblyopia, no differences were found in the responses of PVEP and PERG. On the other hand, the PVEP and PERG latencies were altered between the amblyopic group and the control group. The abnormal components of the PVEP and PERG in amblyopic subjects could reflect a retinal dysfunction in the visual pathway.

\section{Acknowledgments}

The authors would like to express their sincere gratitude to Carlos Alberto Bastos da Silva for his collaboration in conducting the electrophysiological exams. They would also like to express their thanks to Dr Andre Patrão and Niterói Eye Hospital for providing technical support for this project.

\section{Disclosure}

The authors report no conflicts of interest in this work.

\section{References}

1. von Noorden GK. Binocular Vision and Ocular Motility: Theory and Management of Strabismus. 4th ed. St. Louis: CV Mosby; 1990.

2. Barrett BT, Bradley A, McGraw PV. Understanding the neural basis of amblyopia. Neuroscientist. 2004;10(2):106-117.

3. Packwood EA, Cruz OA, Rychwalski PJ, Keech RV. The psychosocial effects of amblyopia study. J AAPOS. 1999;3(1):15-17.

4. Hrisos S, Clarke MP, Wright CM. The emotional impact of amblyopia treatment in preschool children: randomized controlled trial. Ophthalmology. 2004;111(8):1550-1556.

5. Pascual M, Huang J, Maguire MG, et al; Vision In Preschoolers (VIP) Study Group. Risk factors for amblyopia in the vision in preschoolers study. Ophthalmology. 2014;121(3):622-629.e1.

6. Mckean-Cowdin R, Cotter SA, Tarczy-Hornoch K, et al; MultiEthnic Pediatric Eye Disease Study Group. Prevalence of amblyopia or strabismus in Asian and non-Hispanic white preschool children: Multi-Ethnic Pediatric Eye Disease Study. Ophthalmology. 2013; 120(10):2117-2124.

7. Afsari S, Rose KA, Gole GA, et al. Prevalence of anisometropia and its association with refractive error and amblyopia in preschool children. Br J Ophthalmol. 2013;97(9):1095-1099.

8. Hess RF, Thompson B, Baker DH. Binocular vision in amblyopia: structure, suppression and plasticity. Ophthalmic Physiol Opt. 2014; 34(2):146-162.

9. Wong AM, Burkhalter A, Tychsen L. Suppression of metabolic activity caused by infantile strabismus and strabismic amblyopia in striate visual cortex of macaque monkeys. J AAPOS. 2005;9(1):37-47.

10. Ellemberg D, Hess RF, Serge Arsenault AS. Lateral interactions in amblyopia. Vision Res. 2002;42(21):2471-2478.

11. von Noorden GK. Histological studies of the visual sytem in monkeys with experimental amblyopia. Invest Ophthalmol. 1973;12(10): $727-738$.
12. Bruce A, Pacey IE, Bradbury JA, Scally AJ, Barrett BT. Bilateral changes in foveal structure in individuals with amblyopia. Ophthalmology. 2013;120(2):395-403.

13. Wu SQ, Zhu LW, Xu QB, Xu JL, Zhang Y. Macular and peripapillary retinal nerve fiber layer thickness in children with hyperopic anisometropic amblyopia. Int J Ophthalmol. 2013;6(1):85-89.

14. Al-Haddad CE, El Mollayess GM, Mahfoud ZR, Jaafar DF, Bashshur ZF. Macular ultrastructural features in amblyopia using high-definition optical coherence tomography. Br J Ophthalmol. 2013;97(3):318-322.

15. Walker RA, Rubab S, Voll AR, Erraguntla V, Murphy PH. Macular and peripapillary retinal nerve fibre layer thickness in adults with amblyopia. Can J Ophthalmol. 2011;46(5):425-427.

16. Yalcin E, Balci O. Peripapillary retinal nerve fiber layer and foveal thickness in hypermetropic anisometropic amblyopia. Clin Ophthalmol. 2014;8:749-753.

17. Williams C, Papakostopoulos D. Electro-oculographic abnormalities in amblyopia. Br J Ophthalmol. 1995;79(3):218-224.

18. Heravian J, Daneshvar R, Dashti F, et al. Simultaneous pattern visual evoked potential and pattern electroretinogram in strabismic and anisometropic amblyopia. Iran Red Crescent Med J. 2011;13(1):21-26.

19. Lachapelle P. Pattern and focal ERG in amblyopia. Invest Ophthalmol Vis Sci. 1985;26(11):1648-1649.

20. Bach M, Brigell MG, Hawlina M, et al. ISCEV standard for clinical pattern electroretinography (PERG): 2012 update. Doc Ophthalmol. 2013;126(1):1-7.

21. Odom JV, Bach M, Brigell M, et al. ISCEV standard for clinical visual evoked potentials: (2016 update). Doc Ophthalmol. 2016;133(1):1-9.

22. Holder GE, Brigell MG, Hawlina M, Meigen T, Vaegan, Bach M; International Society for Clinical Electrophysiology of Vision. ISCEV standard for clinical pattern electroretinography - 2007 update. Doc Ophthalmol. 2007;114(3):111-116.

23. Pérez-Rico C, García-Romo E, Gros-Otero J, et al. Evaluation of visual function and retinal structure in adult amblyopes. Optom Vis Sci. 2015;92(3):375-383.

24. Yu M, Brown B, Edwards MH. Investigation of multifocal visual evoked potential in ansiometropic and esotropic amblyopes. Invest Ophthalmol Vis Sci. 1998;39(11):2033-2040.

25. Holder GE. The pattern electroretinogram in anterior visual pathway dysfunction and its relationship to the pattern visual evoked potential: a personal clinical review of 743 eyes. Eye (Lond). 1997;11(Pt 6): 924-934.

26. Risse J-F. D'ophtalmologie S française [French opthalmology]. Exploration de la fonction visuelle: Applications au domaine sensoriel de l'oeil normal et en pathologie. 290-292. Paris: Masson; 1999. French.

27. Tugcu B, Araz-Ersan B, Erdogan ET, et al. Structural and functional comparison of the persistent and resolved amblyopia. Doc Ophthalmol. 2014;128(2):101-109.

28. Hess RF, Baker CL Jr, Verhoeve JN, Keesey UT, France TD. The pattern evoked electroretinogram: its variability in normals and its relationship to amblyopia. Invest Ophthalmol Vis Sci. 1985;26(11):1610-1623.

29. Parisi V, Scarale ME, Balducci N, Fresina M, Campos EC. Electrophysiological detection of delayed postretinal neural conduction in human amblyopia. Invest Ophthalmol Vis Sci. 2010;51(10):5041-5048.

30. Simons K. Old age and the functional consequences of amblyopia. J AAPOS. 2008;12(5):429-430.

31. Zhang W, Zhao K. Multifocal VEP difference between early-and late-onset strabismus amblyopia. Doc Ophthalmol. 2005;110(2-3):173-180.

32. Davis AR, Sloper JJ, Neveu MM, Hogg CR, Morgan MJ, Holder GE. Electrophysiological and psychophysical differences between earlyand late-onset strabismic amblyopia. Invest Ophthalmol Vis Sci. 2003; 44(2):610-617.

33. Sanchez I, Ortiz-Toquero S, Martin R, de Juan V. Advantages, limitations, and diagnostic accuracy of photoscreeners in early detection of amblyopia: a review. Clin Ophthalmol. 2016;10:1365-1373. 
Clinical Ophthalmology

\section{Publish your work in this journal}

Clinical Ophthalmology is an international, peer-reviewed journal covering all subspecialties within ophthalmology. Key topics include: Optometry; Visual science; Pharmacology and drug therapy in eye diseases; Basic Sciences; Primary and Secondary eye care; Patien Safety and Quality of Care Improvements. This journal is indexed on

PubMed Central and CAS, and is the official journal of The Society of Clinical Ophthalmology (SCO). The manuscript management system is completely online and includes a very quick and fair peer-review system, which is all easy to use. Visit http://www.dovepress.com/ testimonials.php to read real quotes from published authors. 